\title{
PARECERES
}

\section{IGUALDADE; ISONOMIA TRIBUTÁRIA - DISCRIMINAÇÃO ENTRE MINERAIS DO PAÍS E OUTRAS MERCADORIAS NACIONAIS - INCONSTITUCIONALIDADE DE PROJETO DE LEI COMPLEMENTAR}

A Companhia Vale do Rio Doce encaminhou-me a seguinte

"Consulta

Tramita pela Câmara dos Deputados o Projeto de Lei Complementar n 19, de 1999, com o seguinte teor:

'Art. $1^{\circ}$ Fica incluído o seguinte parágrafo no art. $3^{\circ}$ da Lei Complementar $n^{\circ} 87$, de 13 de setembro de 1996, renumerando-se o parágrafo único:

'Art. $3^{\circ} \ldots$

$\S 2^{\circ} \mathrm{O}$ disposto no inciso II não se aplica às operações que destinem minerais do País ao exterior'.

Art. $2^{\circ}$ Ficam incluídos no art. 32 da Lei Complementar $n^{\circ} 87$, de 13 de setembro de 1996, os seguintes parágrafos:

'Art. 32 ...

$\S 1^{\circ} \mathrm{O}$ disposto no inciso I não se aplica às operações que destinem minerais do País ao exterior.

$\S 2^{\circ} \mathrm{O}$ montante do imposto correspondente às exportações dos produtos mencionados no $\S 1^{\circ}$ não será levado em conta no cálculo da compensação financeira de que tratam o art. 31 e o Anexo desta lei complementar.'

Art. $3^{\circ}$ Esta lei complementar entra em vigor na data de sua publicação".

Aparentemente importando, esse projeto de lei complementar, em discriminação contra os exportadores de minerais do País indaga-se:

o Projeto de Lei Complementar $n^{\circ} 19$, de 1999, é adequado e compatível com a Constituição de 1988 , podendo afirmar-se a sua constitucionalidade?".

Parecer

"O mandamento da Constituição se dirige particularmente ao legislador efetivamente, somente ele poderá ser o destinatário útil de tal mandamento. O executor da lei já está, necessariamente, obrigado a aplicá-la de acordo com os critérios constantes da própria lei" FRANCISCO CAMPOS'.

01. - A igualdade $^{2}$ se expressa em isono-

1 Direito Constitucional, vol. II, Livraria Freitas Bastos S/A, Rio de Janeiro, 1956, p. 188; respeitei a ortografia do original.

2 Observa FRANCISCO CAMPOS (Direito Administrativo, vol. II, Livraria Freitas Bastos S/A, Rio de Janeiro, 1.958, p. 188) ser necessário não confundirmos o princípio da igualdade perante a lei com o princípio da igualdade, sem qualquer qualificação ou restrição, ou enunciado em termos gerais e absolutos. O segundo "representa um ideal, uma aspiração ou um postulado contrário às condições efetivamente existentes na sociedade: ele parte do reconhecimento da existência de desigualdades de fato entre os homens para postular a modificação das relaçōes humanas no sentido de tornar iguais os indivíduos que são efetivamente desiguais. Há uma relação polêmica entre o princípio absoluto de igualdade e o fato das desigualdades reinantes entre os homens. O princípio de igualdade perante a lei, ao contrário, tem conteúdo restrito. ele não pretende alterar as relações efetivamente existentes entre os homens, mas se limita a determinar que a lei tenha em conta, ao regular as relações humanas, as circunstâncias que condicionam efetivamente essas relações ou que não disponha de modo diferente para casos idênticos ou iguais, nem procure igualar o que é, efetivamente, desigual. Ao passo que o princípio absoluto de igualdade tem por fim alterar a estrutura social, intervindo nela para o efeito de suprimir as desigualdades existentes, o 
mia [= garantia de condições idênticas asseguradas ao sujeito de direito em igualdade de condições com outro] e na vedação de privilégios. Decorreria da universalidade das leis - jura non in singulas personas, sed generaliter constituuntur ${ }^{1}$. Reunidos os dois princípios, igualdade e universalidade das leis, assim se traduzem: a lei é igual para todos $e$ todos são iguais perante a le $i^{2}$.

Nem sempre foi assim, contudo. Tal como inscrito nos primeiros textos constitucionais, o princípio da igualdade foi interpretado exclusivamente como determinação de igualdade na aplicação do direito. Essa determinação vincularia unicamente os órgãos que aplicam o direito, não alcançando o legislador $r^{3}$ o que despertou acesa crítica de KELSEN ${ }^{4}$. Após passou ele a ser tomado também como determinação de igualdade na formulação do direito, o que importa em que todos devam ser tratados de modo igual pelo legislador ${ }^{5}$. A anotação de FRANCISCO CAMPOS à pro- pósito, transcrita ao topo deste item, é primorosa.

02. - Dispõe o artigo $5^{\circ}$ da Constituição do Brasil:

"Art. $5^{\circ}$ - Todos são iguais perante a lei, sem distinção de qualquer natureza, garantindo-se aos brasileiros e aos estrangeiros residentes no País a inviolabilidade do direito à vida, à liberdade, à igualdade, à segurança e à propriedade, nos termos seguintes" (grifei).

Encontra-se no enunciado deste artigo $5^{\circ}$, caput - enunciado bem distinto dos que anteriormente, nas nossas Constituições antecedentes, o institucionalizaram (deixo bem vincado este aspecto) - a consagração do princípio da igualdade não apenas em termos formais, mas também em termos materiais. Vale dizer: o que a nova Constituição postula, expressamente, é o entendimento que vinha a doutrina contemplando, segundo o qual a tãosó igualdade perante a lei pouco ou nada significaria ${ }^{6}$. Ela se manifesta, no texto, qual

princípio de igualdade perante a lei visa tão somente assegurar o reconhecimento pela lei das igualdades ou desigualdades que, efetivamente, existem entre os homens. O primeiro é uma ideologia, o segundo um mandamento jurídico de conteúdo limitado e concreto e de valor positivo; o primeiro subordina a realidade a um imperativo destinado a transformá-la, o segundo é uma regra de direito positivo, destinada a limitar ou restringir a ação da lei aos dados da realidade". Dizendo-o de outro modo, afirmarei, singelamente, que o princípio da igualdade perante a lei consubstancia norma jurídica, ao passo que a igualdade - ou princípio da igualdade, tout court - é expressão de um valor, despido porém de conteúdo deontológico (vide meu $O$ direito posto e o direito pressuposto, $2^{2}$ ediçāo, Malheiros Editores, São Paulo, 1998, pp. 78-79).

1 ULPIANO, 1, 3, 10,8.

2 Cf. VICENTE RÁO, O Direito e a vida dos direitos, $1^{\circ}$ vol., Max Limonad, São Paulo, 1960, p. 210.

3 Neste sentido, tratando do direito alemão, ROBERT ALEXY, Theorie der Grundrechte, Suhrkamp, Frankfurt am Main, 1986, pp. 357 e ss.

4 A Justiça e o Direito Natural, Armenio Amado, Coimbra, 1963, p. 66. A igualdade contribui, decisivamente, para conformar o chamado direito moderno, próprio ao modo de produção capitalista. Esse direito pode ser descrito como um universo no qual se movimentam sujeitos jurídicos dotados de igualdade [perante a lei], na prática da liberdade de contratar. Por isso mesmo as normas jurídicas que compõem esse direito são abstratas e gerais, condição necessária a que ele adequadamente viabilize a fluência das relações de mercado.

5 Vide, por todos, FRANCISCO CAMPOS, Direito Administrativo, cit., p. 189-191, e Direito Constitucional, cit., pp. 17 e ss.

6 Observa KELSEN (A Justiça e o Direito Natural, Armenio Amado, Coimbra, 1963, p. 79): "Com efeito, a chamada 'igualdade' perante a lei não significa outra coisa que não seja a aplicação legal, isto é, correta, da lei, qualquer que seja o conteúdo que esta lei possa ter, mesmo que ela não prescreva um tratamento igualitário, mas um tratamento desigual". 
observa JOSÉ SOUTO MAIOR BORGES ${ }^{\text {, }}$ como instrumento de preservação de si própria: a igualdade formal garante a igualdade material e a igualdade material garante a igualdade formal. Não basta que a todos se aplique; é necessário que o seu conteúdo alcance todos igualmente ${ }^{2}$.

03. - A concreção do princípio da igualdade reclama a prévia determinação de quais sejam os iguais e quais os desiguais, até porque - e isso é repetido quase que automaticamente, desde PLATÃO e ARISTÓTELES ${ }^{3}$ - a igualdade consiste em dar tratamento igual aos iguais e desigual aos desiguais.

Vale dizer: o direito deve distinguir pessoas e situações distintas entre si, a fim de conferir tratamentos normativos diversos a pessoas e a situações que não sejam iguais. A questão que fica - crucial - é a seguinte, na dicção de CELSO ANTÔNIO BANDEIRA DE MELLO": "Afinal, que espécie de igualdade veda e que tipo de desigualdade faculta a discriminação de situaçōes e de pessoas, sem quebra e agressão aos objetivos transfundidos no princípio constitucional da isonomia?".

04. - Tudo se torna mais claro na medida em que considerarmos o quanto afirma KELSEN": "os homens (assim como as circunstâncias externas) apenas podem ser considerados como iguais, ou, por outras palavras, apenas há homens iguais (ou circunstâncias externas iguais), na medida em que as desigualdades que de fato entre eles existem não sejam tomadas em consideração. Se não há que tomar em conta quaisquer desigualdades sejam elas quais forem, todos são iguais e tudo é igual". E prossegue, adiante ${ }^{6}$, observando que o princípio "postula não apenas um tratamento igual mas também um tratamento desigual. Por isso, tem de haver uma norma correspondente a este princípio que expressamente defina certas qualidades em relação às quais as desigualdades hão-de ser tidas em conta, afim de que as desigualdades em relação às outras qualidades possam permanecer irrelevantes, a fim de que possam haver de todo em todo, portanto, indivíduos

1 Parecer inédito, sobre a isenção do IOF nas operações de importação. Vide meu $O$ direito posto $e O$ direito pressuposto, ob. cit., pp. 121/122.

2 A propósito, a oportuna observação de JOSÉ SOUTO MAIOR BORGES (idem; ibidem): “Estranha vocação constitucional, a da igualdade. Sobre ser uma norma definidora de um direito (norma que tem aplicabilidade imediata) e um princípio (mais eminente até que os outros princípios do art. $5^{\circ}$ ) é ela ainda um instrumento constitucional de preservação de si própria. É dizer: constitucionalmente a igualdade garante a igualdade material e a igualdade material garante a igualdade formal. Se todos são iguais na aplicação da lei, no sentido de que a lei indiscriminadamente a todos se aplica, mas o seu conteúdo não obriga a isonomia, há violação da igualdade material. Se reversamente lei isonômica a todos não se aplica, nem todos são iguais perante a lei: iguais serão apenas os beneficiários pela aplicação, ficando de fora da isonomia os que o forem. Nessa última hipótese, há violação da igualdade formal. Por isso diz-se que a igualdade garante a igualdade. Essas normas somente podem ser interpretadas uma em conexão com a outra. Se essa conexidade for desconsiderada, abre-se oportunidade à aplicação da igualdade apenas formal (igualdade perante a lei), com prejuízo da igualdade material (igualdade na lei). Torna-se manifesto por essa via que a CF, no seu art. $5^{\circ}$, estrutura a isonomia de modo refinadamente complexo. Primeiro como um direito à reta aplicação da lei (princípio formal). Segundo, como um princípio cujo conteúdo (não a mera forma de sua aplicação portanto) é inegavelmente amplo e até inexceptuável, pela vedação de distinções de qualquer natureza (princípio material e pessoal). Terceiro porque ela regula também os meios assecuratórios desse direito (a lei e outros atos normativos, como as sentenças judiciais)".

3 PLATÃo, Leis, VI 757; ARISTÓTELES, Política, III 9 (1280a) e Ética a Nicômano, V 6 (1131a).

4 O conteúdo jurídico do princípio da igualdade, Editora Revista dos Tribunais, São Paulo, 1978, pp. $15 / 16$.

5 Ob. cit., p. 67.

6 Idem, pp. 70/71. 
'iguais'. 'Iguais' são aqueles indivíduos que, em relação às qualidades assim determinadas, não são desiguais. E o poderem, de todo em todo, existir indivíduos 'iguais', é a consequiência do fato de que, se não todas, pelo menos certas desigualdades não são consideradas" (grifo no original) ${ }^{\mathrm{l}}$.

Por isso mesmo pode, a lei - como qualquer outro texto normativo - sem violação do princípio da igualdade, distinguir situações. a fim de conferir a uma tratamento diverso do que atribui a outra. Para que possa fazê-lo, contudo, sem que tal violação se manifeste, é necessário que a discriminação guarde compatibilidade com o conteúdo do princípio.

Procurando dar resposta à indagação à respeito de quais situações e pessoas podem ser discriminadas sem quebra e agressão aos objetivos transfundidos no princípio constitucional da isonomia, a jurisprudência do Tribunal Constitucional alemão toma como fio condutor a seguinte frase: "a máxima da igualdade é violada quando para a diferenciação legal ou para o tratamento legal igual não seja possível encontrar uma razão razoável, que surja da natureza da coisa ou que, de alguma forma, seja compreensível, isto é, quando a disposição tenha de ser qualificada de arbitrária" ${ }^{2}$.

Dir-se-á, pois, que uma discriminação será arbitrária quando "não seja possível encontrar, para a diferenciação legal, alguma razão razoável que surja da natureza das coisas ou que, de alguma forma, seja concretamente compreensível" 3 .

Tratando do tema, em ensaio exemplar, CELSO ANTÔNIO BANDEIRA DE MEL-
$\mathrm{LO}^{4}$ observa que o reconhecimento das diferenciações que não podem ser feitas sem quebra da isonomia envolve a ponderação de três questões: "tem-se que investigar, de um lado, aquilo que é adotado como critério discriminatório; de outro lado, cumpre verificar se há justificativa racional, isto é, fundamento lógico, para, à vista do traço desigualador acolhido, atribuir o específico tratamento jurídico construído em função da desigualdade proclamada. Finalmente, impende analisar se a correlação ou fundamento racional abstratamente existente é 'in concreto', afinado com os valores prestigiados no sistema normativo constitucional. A dizer: se guarda ou não harmonia com eles" 5 .

05. - Além do artigo $5^{\circ}$ da Constituição de 1988, também o seu artigo 150, II contempla a igualdade, aqui tomada como isonomia tributária:

"Art. 150 - Sem prejuízo de outras garantias asseguradas ao contribuinte, é vedado à União, aos Estados, ao Distrito Federal e aos Municípios:

\section{(............)}

II - instituir tratamento desigual entre contribuintes que se encontrem em situação equivalente, proibida qualquer distinção em razão de ocupação profissional ou função por eles exercida, independentemente da denominação jurídica dos rendimentos, títulos e direitos;".

Essa reiteração da isonomia no setor tributário não é redundante ou supérflua, dado que aqui, nesse artigo 150 , a vedação da discriminação entre contribuintes que se encontrem em situação equivalente não consubstancia

1 Daí a observação de FÁBIO KONDER COMPARATO (Direito Público - Estudos e Pareceres, Saraiva, São Paulo, 1996, p. 135): “É antes mister, como salienta o Prof. Konrad Hesse, procurar entender, preliminarmente, o que seja a igualdade jurídica, que não se confunde com a identidade. Se duas situações a serem normadas ou decididas fossem idênticas, não haveria, obviamente, nenhum problema jurídico a resolver, quer de legislação, quer de aplicação da lei. A igualdade jurídica supōe, portanto, logicamente, alguma diferença entre uma situação e outra, entre uma hipótese de incidência e outra".

2 Cf. ROBERT ALEXY, ob. cit., p. 366.

3 Idem, p. 370.

4 O conteúdo do princípio da igualdade, Editora Revista dos Tribunais, São Paulo, 1978.

5 Ob. cit., pp. $27 / 28$. 
apenas um direito fundamental, mas também é afirmada como uma das limitações constitucionais ao poder de tributar ${ }^{1}$. Todas as observações atinentes à igualdade, como contemplada no artigo $5^{\circ}$, não obstante se amoldam ao instituto da isonomia tributária.

Assim, como anota ANTÔNIO ROBERTO SAMPAIO DÓRIA ${ }^{2}$, a exigência de igualdade fiscal deve "se conformar e harmonizar com as desigualdades econômicas, ou de outra natureza, em função das quais, e somente delas, o poder tributário se há de exercitar com justiça" 3 .

Quanto à indagação à respeito de quais contribuintes podem ser discriminados sem quebra e agressão aos objetivos da isonomia tributária, aludindo ao Justice BRANDEIS, da Suprema Corte norte-americana, insiste SAMPAIO DÓRIA em que se exige meramente que a discriminação seja razoável, sendo razoável a "classificação que um homem bem informado, inteligente, de bom senso e civilizado possa racionalmente prestigiar" ${ }^{4}$. E os seguintes fatores devem ser considerados: a) razoabilidade da discriminação, baseada em diferenças reais entre as pessoas ou objetos taxados; b) existência de objetivo que justifique a discriminação; c) nexo lógico entre o objetivo perseguido e a discriminação que permitirá alcançá-lo ${ }^{5}$.

06. - A Lei Complementar $n^{\circ} 87$, de 13 de setembro de 1996, dispõe sobre o imposto dos Estados e do Distrito Federal sobre operações relativas à circulação de mercadorias e sobre prestações de serviços de transporte interestadual e intermunicipal e de comunicação, definindo, seu artigo $3^{\circ}$, II, que o tributo não incide sobre operações e prestações que destinem ao exterior mercadorias, inclusive produtos primários e produtos industrializados semi-elaborados, ou serviços.

O projeto de lei de que cuido discrimina, apontando-os como desiguais em relação às demais mercadorias destinadas ao exterior, para os efeitos de não incidência do ICMS, os "minerais do País".

A estes impõe, o projeto de lei complementar, o gravame da incidência tributária.

A questão a solucionar, pois, é a seguinte: deve, a desigualdade que de fato existe entre a generalidade das mercadorias e os minerais do País, ser tomada em consideração para tal efeito (efeito de serem os derradeiros, gravados pelo ICMS nas operações os destinem ao exterior)?

E aqui, paralelamente, dois outros aspectos devem ser ponderados:

(a) há relação de pertinência lógica entre o fator diferencial adotado pelo projeto de lei complementar (ser mineral do País) e sua inclusão no gravame imposto (sofrer $a$ incidência do ICMS nas operações os destinem ao exterior $)^{6}$ ?

(b) o nexo estabelecido entre a desigualdade considerada e o tratamento jurídico diferenciado é compatível com interesses acolhidos no sistema constitucional?

Do enunciado das respostas a serem confe-

I Daí afirmar SOUTO MAIOR BORGES (conferência publicada in Revista de Direito Tributário, 64, p. 14) que "a suprema limitação do poder de tributar é a isonomia. Portanto, nenhuma lei tributária material sem isonomia, nenhum tributo sem legalidade".

2 Princípios Constitucionais Tributários e a Cláusula Due Process of Law, Editora Revista dos Tribunais, São Paulo, 1964, p. 193.

3 Prossegue o autor (ob. cit., idem): "Esta concepção do princípio da igualdade exprime-se, na esfera tributária, pela conclusão de que a taxação deve ser idêntica para as pessoas ou atividades igualmente situadas e desigual para aquelas que entre si desigualem e, se possivel, na exata medida da desigualdade apurada".

4 Ob. cit., p. 195

5 Idem, p. 196.

6 Vide CELSO ANTÔNIO BANDEIRA DE MELLO, ob. cit., p. 49.

7 Idem, p. 54 
ridas a tais questões resultará demonstrada a constitucionalidade, ou a inconstitucionalidade, do projeto de lei complementar.

07. - Diz a justificação que acompanhou o projeto de lei complementar que a isenção concedida à exportação de produtos primários deveria ter sido restringida aos "produtos renováveis, isto é, aos produtos de origem agropecuária”. E prossegue:

"Aos produtos não-renováveis, como os minerais, não deveria ter sido deferida a desoneração. Em primeiro lugar porque, como o próprio nome diz, esses produtos, uma vez extraídos e exportados, representam parte de nossa riqueza que se foi e que não se pode repor. Em segundo lugar, a tributação sobre esses produtos poderia induzir a algum tipo de beneficiamento que, agregando valor, melhor aproveitasse a matéria-prima, dando postos de trabalho a brasileiros, e não a estrangeiros. Em terceiro lugar, deve-se considerar que a exportação de produtos 'in natura' ou de pouco beneficiamento representa a forma menos benéfica de exploração do sub-solo para a economia do setor público. Estados e Municípios necessitam de maiores recursos, que poderiam ser proporcionados em parte pela receita de exportação, para fazer frente às despesas provocadas pelos danos ambientais e pelos aglomerados populacionais relacionados com a exploração mineral".

Não me cabe tecer qualquer comentário, nesta ocasião, à respeito do mérito das três razões pelas quais, segundo o autor do projeto de lei complementar, aos "produtos não-renováveis, como os minerais, não deveria ter sido deferida a desoneração". Importa no entanto lembrar que a Lei Complementar $\mathrm{n}^{\circ}$ $87 / 96$ consagrou uma política de fomento às exportações caracterizada precisamente pela circunstância de abranger todas as mercadorias exportadas, sem exclusão dos produtos primários e semi-industrializados. Daí a importância em deixarmos bem vincado este aspecto: o projeto importa em alteração dessa política, discriminando os minerais do País, que seriam excluídos do benefício consistente na não incidência do ICMS.

08. - A leitura da justificativa do projeto de lei complementar mostra bem que o fator que diferencia os minerais do País das demais mercadorias é exclusivamente o atinente à circunstância de eles serem " produtos não-renováveis". Pois é certo que as peculiaridades consideradas nas duas últimas razões adotadas para justificar porque não deveria ter sido deferida a desoneração do ICMS em relação aos minerais do País são comuns a eles e aos demais produtos primários - a tributação sobre todos os produtos primários induziria "a algum tipo de beneficiamento que, agregando valor, melhor aproveitasse a matéria-prima, dando postos de trabalho a brasileiros, e não a estrangeiros"; a exportação de quaisquer produtos primários poderia proporcionar os recursos de que carecem Estados e Municípios!.

Assim, o fator diferencial adotado pelo projeto de lei complementar para discriminar os minerais do País encontra-se na circunstância de que eles, sendo não-renováveis, "uma vez extraídos e exportados, representam parte de nossa riqueza que se foi e não se pode repor". Essa circunstância consubstancia o único fator diferencial útil à tentativa de justificação da exclusão dos minerais do País ao benefício da não incidência do ICMS nas operações que os destinem ao exterior.

09. - Sucede que o projeto de lei complementar respeita unicamente aos minerais do País enquanto produtos primários, não obstante representem "parte de nossa riqueza que se foi e não se pode repor" ainda quando sejam exportados não "in natura", mas já beneficiados ou mesmo agregados a produtos industrializados.

Por aí se vê, com nitidez, que seguramente não há relação de pertinência lógica entre o fator diferencial adotado pelo projeto de lei complementar e a inclusão dos por ele afeta-

1 Não está explicitado na justificativa porque “a exportação de produtos 'in natura' ou de pouco beneficiamento representa a forma menos benéfica de exploração do subsolo para a economia do setor público". 
dos no gravame imposto. Isso, como se viu, é francamente evidente.

Por que, entre as mercadorias [do País], exclusivamente os minerais "in natura" não deveriam, quando objeto de operações e prestações que os destinem ao exterior, beneficiarse da não incidência do tributo? Por serem produtos "não-renováveis"?

Por certo que não, visto que não deixam de ser também "não-renováveis" os minerais semi-industrializados ou agregados, como matéria-prima, a produtos industrializados mas que, não obstante, permanecerão a ser beneficiados pela não incidência do ICMS.

Ora, se também peculiariza os minerais utilizados em processos de industrialização o fato de serem não-renováveis, evidentemente não tem cabimento a utilização dessa peculiaridade [não ser renovável] para que se exclua os minerais do País ao benefício definido no artigo $3^{\circ}$, II da Lei Complementar $n^{\circ} 87 / 96$, benefício que - repita-se - alcança os minerais do País quando não "in natura".

Por isso a discriminação é gratuita. Inexiste, aqui, na expressão de CELSO ANTÔNIO BANDEIRA DE MELLO', "adequação racional entre o tratamento diferençado construído e a razão diferencial que lhe serviu de supedâneo". Em outros termos: suportar a incidência do ICMS nas operações que os destinem ao exterior não consubstancia estatuição (Rechtsfolge) que guarde a necessária relação de pertinência lógica com a hipótese ou pressuposto de fato (Tatbestand) "ser mineral [não-renovável] do país" 2 .

10. - De outra parte, o nexo estabelecido entre a desigualdade considerada (ser mineral do país) e o tratamento jurídico diferenciado (sofrer a incidência do tributo) não é compatível com interesses acolhidos no sistema constitucional.

Bem ao contrário disso, é incompreensível que se exclua de política voltada à promoção das exportações, adequada aos preceitos veiculados especialmente pelos artigos $3^{\circ}$ e 170 da Constituição de 1988, essas mercadorias.

Ainda aqui, quanto a isso, creio não existir contestação plausível, mesmo porque nenhuma das razões adotadas na justificativa do projeto a sustentaria.

Daí porque a questão postulada no item 06, acima, há de ser respondida de modo negativo: a desigualdade que de fato existe entre os minerais do País e as demais mercadorias não deve ser tomada em consideração para o efeito de que incida sobre os primeiros o ICMS.

$O$ fato é que não se toma possivel encontrarmos uma "razão razoável" para tanto. Vale dizer: a discriminação contra os minerais do País é arbitrária.

11. - Mas não é só.

Cumpre também, de outra banda, afirmar que - além da discriminação não ser razoável, porque não está baseada em diferenças reais entre os minerais do País e as demais mercadorias alcançadas pela não incidência do ICMS - inexiste, no caso, objetivo que justifique a discriminação.

Deveras, esse objetivo seria o de dificultar a exportação de produtos que "uma vez extraídos e exportados, representam parte de nossa riqueza que se foi e que não se pode repor", sendo contudo evidente que minerais [do País] semi-industrializados ou agregados,

\section{Idem, p. 49.}

2 Refiro-me, aqui, ao fato de a norma jurídica [proposiçāo normativa] ser dotada de uma estrutura peculiar: representa determinada situação objetiva, hipotética [o Tatbestand, hipótese, pressuposto de fato, facti species] à qual estão ligadas certas consequiências práticas, ou seja, os efeitos por ela prescritos [Rechtsfolge, estatuição, injunção]. A norma jurídica prescreve os efeitos enunciados na estatuição ou injunção em relação à situação de fato que prevê possa vir a se verificar, desde que ela se verifique. Por isso é dotada de caráter logicamente hipotético: enuncia hipótese que produz consequiências jurídicas [cf. CASTANHEIRA NEVES, Curso de introduçāo ao estudo do Direito, ed. policopiada, Coimbra, 19711972, p. 269]. O caráter formal das proposições jurídicas é expresso na conexão entre uma hipótese e uma estatuição de consequiência jurídica [cf. KARL LARENZ, Methodenlehre der Rechtswissenschafi, $5^{*}$ ed., Springer, Berlim, 1.983, p. 33]. 
como matéria-prima, a produtos industrializados uma vez exportados também representam - repita-se - "parte de nossa riqueza que se foi e que não se pode repor".

A ausência de diferenças reais entre os minerais do País e os demais produtos primários alcançados pela não incidência do ICMS torna injustificáveis, carentes de fundamento lógico, tanto a discriminação entre ambos [minerais e demais produtos primários], quanto a outra, mais ampla, discriminação entre mercadorias [do País] e minerais do País. Daí porque sustento inexistir, no caso, objetivo que justifique a discriminação.

Ora, inexistindo objetivo que justifique a discriminação, não há como indagarmos da existência de nexo lógico entre objetivo inexistente e a discriminação consumada.

12. - A inconstitucionalidade do projeto de lei complementar parece-me, destarte, inquestionável. Consubstancia, no meu entendimento - e em razão de tudo quanto acima ponderei - grave ofensa ao princípio da igualdade.
A exclusão dos minerais do País à não incidência do ICMS importa em afronta à isonomia, tanto na sua amplitude maior de abrangência, quanto, especificadamente, enquanto expresso como princípio da igualdade de todos perante as cargas públicas, princípio que, tratando-se de cargas monetárias, não apenas se dessume da própria ordem constitucional, mas também é extraído à disposição expressa do artigo 150, II do texto constitucional.

13. - Em face do exposto, respondo ao quesito proposto afirmando a inconstitucionalidade do projeto de lei complementar e, logo, sua incompatibilidade com a ordem constitucional.

É o que me parece

São Paulo, 7 de dezembro de 1999

Eros Roberto Grau

Professor Titular da Faculdade de Direito da USP

Professor Visitante da Faculdade de Direito da USP da Universidade de Montpellier I (França) [1995-1998] 